\title{
MICROESTRUTURA E PROPRIEDADES MECÂNICAS DE HIDROGÉIS COMPÓSITOS DE CELULOSE BACTERIANA E ALOE VERA.
}

\author{
J. F. GODINHO ${ }^{1}$, D. MÜLLER ${ }^{2}$, F. V. BERTI ${ }^{1}$, C. R. RAMBO ${ }^{3}$, C. Q. PAES ${ }^{1}$, L. M. PORTO ${ }^{1}$
}

${ }^{1}$ Universidade Federal de Santa Catarina, Departamento de Engenharia Química e Engenharia de Alimentos

${ }^{2}$ Universidade Federal de Santa Catarina, Departamento de Engenharia de Materiais

${ }^{3}$ Universidade Federal de Santa Catarina, Departamento de Engenharia Elétrica

E-mail para contato: \{joanna, daliana, fernanda, rambo, camilaquinetti, luismar\}@intelab.ufsc.br

RESUMO - O desenvolvimento de scaffolds sintéticos, que mimetizem a matriz extracelular para promover a regeneração tecidual, tem sido foco intenso de estudo. Este trabalho tem como objetivo a produção e a caracterização microestrutural e mecânica de membranas de celulose bacteriana (CB), incorporadas com polissacarídeos de Aloe vera. A Aloe vera foi incorporada na $\mathrm{CB}$ através da incorporação in situ de frações polissacarídicas em concentrações de 20,40 e $60 \%$. As amostras foram caracterizadas morfologicamente por microscopia eletrônica de varredura e quanto às propriedades mecânicas, através de ensaios de tração. Foram obtidas membranas com propriedades mecânicas distintas para cada composição. As membranas apresentaram uma microestrutura composta de nanofibras randomicamente distribuídas. O aumento da concentração de Aloe ocasionou um decréscimo na resistência à tração dos biomateriais. As membranas compósitas apresentaram propriedades promissoras para aplicações na engenharia de tecidos.

\section{INTRODUÇÃO}

A engenharia de tecidos abrange a aplicação de conhecimentos multidisciplinares para o desenvolvimento de biomateriais capazes de restaurar a função de tecidos e órgãos. Diversos materiais têm sido propostos, dentre eles a celulose bacteriana (CB), que tem sido ressaltada por sua microestrutura e propriedades mecânicas singulares que se assemelham à matriz extracelular. A CB é produzida por bactérias, do gênero Gluconacetobacter, em forma de nanofibras randomicamente distribuídas que interconectadas formam uma rede fibrosa tridimensional ultrafina. As propriedades da CB podem ser aprimoradas para melhor adequação a aplicabilidade em um tecido alvo através da incorporação de outros compostos na sua produção.

A Aloe vera, popularmente denominada babosa no Brasil, é uma planta utilizada na medicina popular por suas propriedades terapêuticas e medicinais. Essa planta possui uma ampla 


\section{9 a 22 de outubro de 2014 \\ Florianópolis/SC}

gama de atividades biológicas benéficas à saúde humana, como ações antiinflamatória, cicatrizante e estimuladora do sistema imune, devido à complexa combinação de compostos presentes no seu gel interno. A incorporação do gel desta planta em biomateriais, como a CB, pode conferir propriedades únicas capazes de melhorar a biocompatibilidade e proporcionar efeitos terapêuticos isentos nos biomateriais puros de CB.

Este trabalho tem por objetivo produzir e caracterizar materiais a base de CB incorporados com três frações extraídas da Aloe vera: fração enriquecida de polissacarídeos (F), o gel total da polpa da planta contendo fibras (T) e o gel isento de fibras da planta $(\mathrm{G})$. Esses materiais foram produzidos com a adição in situ de frações de Aloe vera em concentrações de 20, 40 e 60\%. Ao final do período de produção, esses hidrogéis foram caracterizados quanto ao módulo de elasticidade, tensão e alongamento de ruptura, através de ensaios de tração, e à microestrutura, através da microscopia eletrônica de varredura (MEV).

\section{MATERIAIS E MÉTODOS}

\subsection{Produção e purificação dos hidrogéis}

Para a produção dos hidrogéis a base de celulose bacteriana foi utilizado um meio de cultura contendo $25 \mathrm{~g} \cdot \mathrm{L}^{-1}$ de manitol, $3 \mathrm{~g} \cdot \mathrm{L}^{-1}$ de peptona e $5 \mathrm{~g} \cdot \mathrm{L}^{-1}$ de extrato de levedura. Esses componentes foram diluídos em $1 \mathrm{~L}$ de água destilada, o pH dessa solução foi ajustado para 6,5 e em seguida esta foi autoclavada. Hidrogéis isentos de frações de Aloe vera foram utilizados como controle.

Os hidrogéis controle de CB foram preparados com a adição de $90 \%$ (v/v) do meio de cultura à base de manitol $(\mathrm{MCM})$ e $10 \%(\mathrm{v} / \mathrm{v})$ de uma solução estoque de inóculo (SEI) contendo a bactéria Gluconacetobacter hansenii ATCC 23769. Os demais meios de cultura contendo $A$. vera foram preparados, conforme descrito na Tabela 1 , homogeneizados e para cada formulação do meio de manitol/A. vera foi adicionado $10 \%(\mathrm{v} / \mathrm{v})$ de inóculo da bactéria $G$. hansenii. Para incorporação das frações de Aloe vera na síntese in situ da $\mathrm{CB}$ foi preparada uma solução de $1 \mathrm{~g} . \mathrm{L}^{-1}$ de fração $\mathrm{F}$, que posteriormente seguiu para autoclavagem, juntamente com as frações $\mathrm{T}$ e G.

Para síntese dos hidrogéis, as culturas foram mantidas em placas de cultura de 24 poços (TPP, Switzerland), devidamente identificadas. Em cada poço, foi adicionado $1 \mathrm{~mL}$ de cada formulação. Os hidrogéis foram formados em 10 dias na interface ar/líquido, mantidos à temperatura ambiente e sob condições estáticas. Após o período de cultura, os hidrogéis foram retirados das placas e submetidos à purificação com solução de $\mathrm{NaOH} 0,1 \mathrm{M}$, durante 24 horas a $50{ }^{\circ} \mathrm{C}$. Logo após, os hidrogéis foram retirados da solução alcalina e lavados com água destilada. Ao final, o $\mathrm{pH}$ da água contendo os hidrogéis foi ajustado para 7,4 seguindo então para a esterilização através de autoclavagem. 
Tabela 1 - Formulações dos hidrogéis de celulose bacteriana (\% v/v): a) fração enriquecida de polissacarídeos, b) gel isento de fibras da planta, c) gel total da polpa da planta contendo fibras,

d) solução estoque de inóculo e e) meio de cultura à base de manitol.

\begin{tabular}{|c|c|c|c|}
\hline \multirow{2}{*}{ Formulação } & \multicolumn{3}{|c|}{ Hidrogéis de Celulose Bacteriana (CB) } \\
\cline { 2 - 4 } & $\mathrm{CB}-\mathrm{F}$ & $\mathrm{CB}-\mathrm{G}$ & $\mathrm{CB}-\mathrm{T}$ \\
\hline $0 \%$ & \multicolumn{3}{|c|}{$10 \% \mathrm{SEI}+90 \% \mathrm{MCM}$} \\
\hline \multirow{2}{*}{$20 \%$} & $\begin{array}{c}10 \% \mathrm{SEI}^{\mathrm{d}}+70 \% \\
\mathrm{MCM}^{\mathrm{e}}+20 \% \mathrm{~F}^{\mathrm{a}}\end{array}$ & $\begin{array}{c}10 \% \mathrm{SEI}+70 \% \mathrm{MCM} \\
+20 \% \mathrm{G}^{\mathrm{b}}\end{array}$ & $\begin{array}{c}10 \% \mathrm{SEI}+70 \% \mathrm{MCM} \\
+20 \% \mathrm{~T}^{\mathrm{c}}\end{array}$ \\
\hline \multirow{2}{*}{$40 \%$} & $\begin{array}{c}10 \% \mathrm{SEI}+50 \% \mathrm{MCM} \\
+40 \% \mathrm{~F}\end{array}$ & $\begin{array}{c}10 \% \mathrm{SEI}+50 \% \mathrm{MCM} \\
+40 \% \mathrm{G}\end{array}$ & $\begin{array}{c}10 \% \mathrm{SEI}+50 \% \mathrm{MCM} \\
+40 \% \mathrm{~T}\end{array}$ \\
\hline \multirow{2}{*}{$60 \%$} & $\begin{array}{c}10 \% \mathrm{SEI}+30 \% \mathrm{MCM} \\
+60 \% \mathrm{~F}\end{array}$ & $\begin{array}{c}10 \% \mathrm{SEI}+30 \% \mathrm{MCM} \\
+60 \% \mathrm{G}\end{array}$ & $\begin{array}{c}10 \% \mathrm{SEI}+30 \% \mathrm{MCM} \\
+60 \% \mathrm{~T}\end{array}$ \\
\hline
\end{tabular}

\subsection{Caracterização dos hidrogéis}

Previamente à análise de microscopia eletrônica de varredura, os hidrogéis foram congelados em um freezer a $-80^{\circ} \mathrm{C}$ (marca Nuaire, modelo NU-9483GC), por aproximadamente 24 horas, e liofilizados $(24 \mathrm{~h})$ em equipamento Liotop, modelo L101, no Laboratório de Tecnologias Integradas (InteLab/UFSC). Posteriormente os hidrogéis foram metalizados com ouro para análise de MEV, utilizando o equipamento Jeol 6390 LV (JEOL Ltd., Tokio, Japão) a uma tensão de $10 \mathrm{kV}$.

As propriedades mecânicas dos hidrogéis de CB foram determinadas em um texturomêtro Stable Micro Systems (TA.XT Plus, Inglaterra), utilizando o software Exponent Stable Micro Systems v. 5.1.1.0 com uma célula de carga de $500 \mathrm{~N}$. Para essa análise foram utilizadas três unidades de cada hidrogel, de dimensões $90 \mathrm{~mm}$ de comprimento por $15 \mathrm{~mm}$ de largura. A espessura de cada hidrogel foi determinada utilizando um paquímetro, após o cálculo da média de três medidas repetidas aleatoriamente. A separação inicial entre as garras e a velocidade do teste foram de $50 \mathrm{~mm}$ e $0,05 \mathrm{~mm} \cdot \mathrm{s}^{-1}$, respectivamente. Os módulos de tensão de ruptura, alongamento à ruptura e módulo de elasticidade foram determinados através das curvas de tensão-deformação.

Os dados foram avaliados estatisticamente utilizando-se o software Statistica 7.0 (StatSoft Software, Tulsa, OK, USA). Os resultados experimentais foram expressos como a média \pm erro padrão da média (EPM) e comparados através da análise de variância one-way (ANOVA) seguida pelo teste Tukey considerando-se estatisticamente diferentes para $p<0,05$.

\section{RESULTADOS}

As Figuras 1, 2 e 3 mostram variação da microestrutura dos hidrogéis produzidos em função da adição de frações de Aloe vera no meio de cultura. 
A Figura 1 mostra a microestrutura típica do hidrogel de $\mathrm{CB}$, no qual (a) representa a fratura transversal da membrana, (b) a superfície superior e (c) a superfície inferior. A superfície que se forma na interface ar/líquido (b) apresenta uma rede com alta densidade de fibras, seguida por uma rede porosa, com poros de tamanhos variados, que se estende até a face em contato com o líquido (c), com fibras livremente orientadas. O hidrogel suplementado com $20 \%$ de fração $F$ (CB-20F d-f) possui a microestrutura da superfície superior (e) e interna (d) bastante similar à da CB pura; entretanto, sua superfície inferior exibe menor densidade de fibras (f). CB-40F e CB60F possuem densidade de fibras similar à $\mathrm{CB}$ pura na superfície inferior (i e h). No entanto, a seção transversal revela que existe uma tendência à organização de uma microestrutura interna ( $\mathrm{g}$ e j), com poros mais definidos, sendo que a superfície superior possui maior heterogeneidade, com alta densidade de fibras, e espaçamento maior entre elas (h e l).
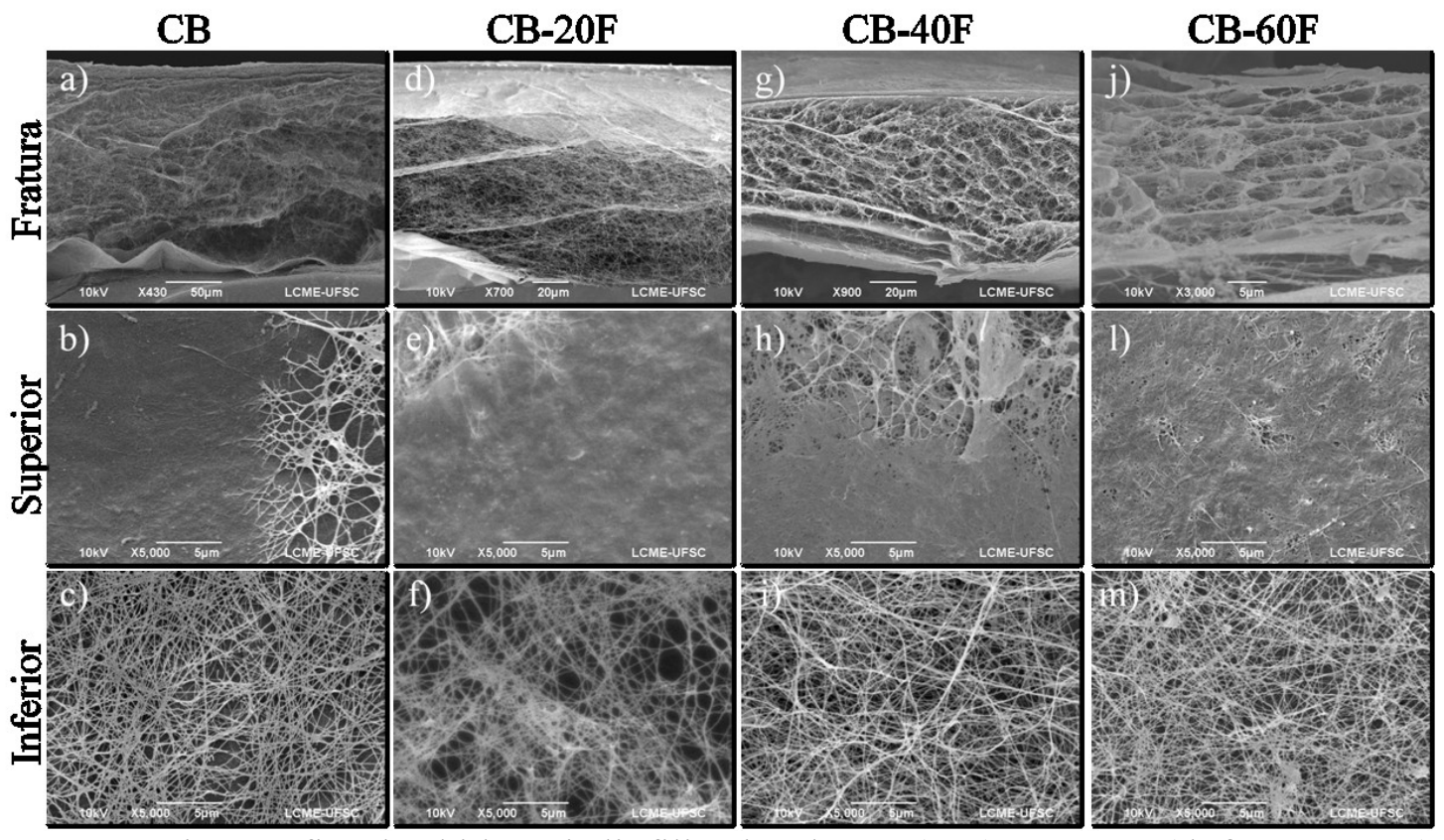

Figura 1 - Micrografias dos hidrogéis liofilizados de CB (a-c), CB-20F (d-f), CB-40F (gi) e CB-60F $(j-m)$ evidenciando: fratura, face inferior e face superior. Magnitudes de ampliação a) $430 \times$, b) $5.000 \times$, c) $5.000 \times$, d) $700 \times$, e) $5.000 \times$, f) $5.000 \times$, g) $900 \times$, h) $5.000 \times$, i) $5.000 \times$, j) $3.000 \times$, l) $5.000 \times$ e m) $5.000 \times$.

A Figura 2 mostra a microestrutura dos hidrogéis produzidos com formulações à base da fração $G$, ou seja, os hidrogéis CB-G. A superfície superior das três formulações utilizadas, 20, 40 e $60 \%(b, e, h)$ exibe uma estrutura homogênea sem grandes poros. O corte sagital (a, d, g) das membranas apresenta uma rede porosa interconectada por uma formação lamelar fina como uma malha que se estende até a face inferior (c, f, i). Na face inferior os poros são preenchidos com uma malha de nanofibras. 


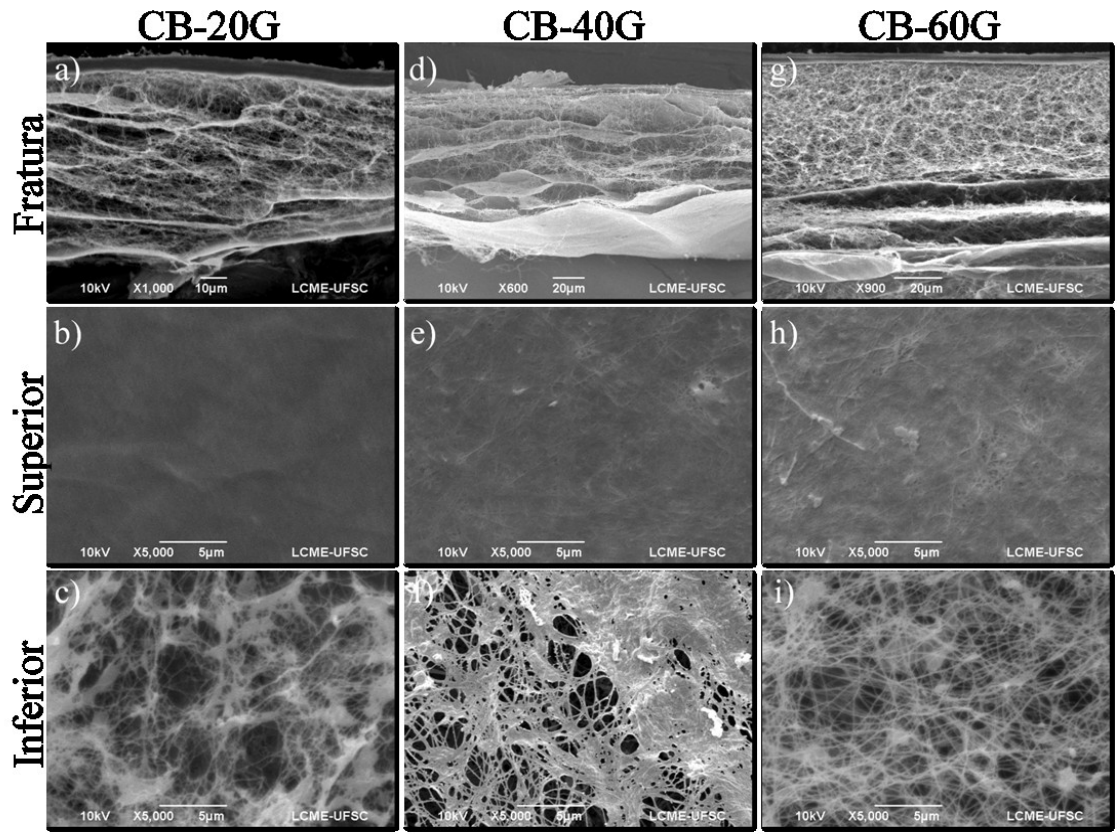

Figura 2 - Micrografias dos hidrogéis liofilizados de CB-20G (a-c), CB-40G (d-f) e CB-60G (g-

i) evidenciando: fratura, face inferior e face superior. Magnitudes de ampliação a) $1.000 \times$, b) $5.000 \times$, c) $5.000 \times$, d) $600 \times$, e) $5.000 \times$, f) $5.000 \times$, g) $900 \times$, h) $5.000 \times$ e i) $5.000 \times$.

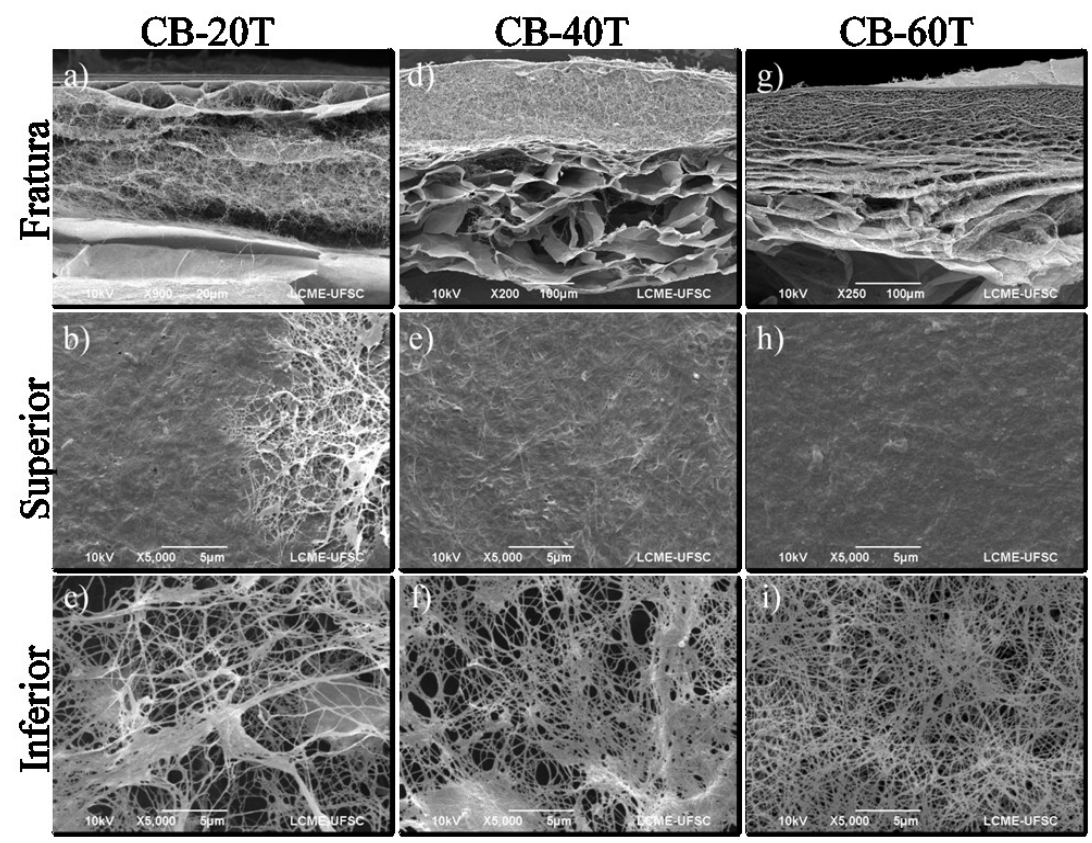

Figura 3 - Micrografias dos hidrogéis liofilizados de CB-20T (a-c), CB-40T (d-f) e CB-60T (gi) evidenciando: fratura, face inferior e face superior. Magnitudes de ampliação a) $900 \times$, b) $5.000 \times$, c) $5.000 \times$, d) $200 \times$, e) $5.000 \times$, f) $5.000 \times$, g) $250 \times$, h) $5.000 \times$ e i) $5.000 \times$. 


\section{9 a 22 de outubro de 2014 \\ Florianópolis/SC}

A microestrutura dos hidrogéis produzidos com diferentes concentrações da fração T está mostrada na Figura 3. A superfície superior do hidrogel CB-20T (b) apresenta uma estrutura semelhante à mesma superfície da CB pura (Fig. 1 b) e o corte transversal (a) se assemelha a estrutura interna dos hidrogéis modificados com a fração G (Figura 2). A superfície inferior (c) também possui microfibrilas que preenchem os poros e recobrem as fibras. A superfície superior de CB-40T (e) e CB-60T (h) é similar à superfície das amostras sintetizadas com diferentes frações da porção G. O corte sagital do hidrogel CB-40T (d) revelou uma microestrutura com distribuição vertical contínua da porosidade. As fibras estão distribuídas e interconectadas em três camadas distintas, no qual a primeira camada é constituída por uma superfície com alta densidade de fibras, seguida por uma camada de porosidade intermediária quando comparada ao tamanho de poros da última camada. A presença de lamelas ou compartimentos maiores é observada na última camada, que possui uma rede de microfibrilas interconectadas até a face inferior (i). O corte sagital de CB-60T (g) mostra que a microestrutura é ordenada em pequenos poros no topo, interconectados por finas lamelas, que gradativamente aumentam de tamanho até a face inferior. A superfície inferior é constituída por uma rede fibrosa, mas não possui microfibrilas interligando as fibras maiores.

As propriedades mecânicas dos hidrogéis sintetizados com e sem $A$. vera estão apresentadas na Tabela 2. O hidrogel de CB evidenciou menor deformação, maior tensão de ruptura e módulo de elasticidade dentre todas as amostras (exceto CB-20G). À medida que a concentração da suplementação do meio de cultura aumenta, o alongamento de ruptura dos hidrogéis se eleva a valores significativamente $(\mathrm{p}<0,05)$ maiores para as amostras modificadas com $40 \%$ e $60 \%$ das frações. O módulo de elasticidade foi significativamente reduzido $(\mathrm{p}<0,05)$ com a inserção de frações de Aloe vera, em praticamente todas as amostras, exceto a CB-20G.

Tabela 2 - Propriedades mecânicas dos hidrogéis de CB. Dados representados com a média \pm $\operatorname{EPM}(* \mathrm{p}<0,05)$.

\begin{tabular}{|c|c|c|c|}
\hline Amostras & $\begin{array}{l}\text { Módulo de elasticidade } \\
\qquad(\mathrm{kPa})\end{array}$ & $\begin{array}{l}\text { Alongamento até a } \\
\text { ruptura }(\%)\end{array}$ & $\begin{array}{l}\text { Tensão de ruptura } \\
\qquad(\mathrm{kPa})\end{array}$ \\
\hline CB & $26,89 \pm 2,17$ & $21,11 \pm 0,73$ & $482,88 \pm 35,41$ \\
\hline CB-20F & $11,41 \pm 0,07 *$ & $39,49 \pm 1,07$ & $342,40 \pm 14,10$ \\
\hline CB-40F & $13,37 \pm 1,44^{*}$ & $58,74 \pm 3,33 *$ & $406,15 \quad \pm 51,75$ \\
\hline CB-60F & $7,79 \pm 0,32^{*}$ & $61,61 \pm 3,92 *$ & $262,72 \pm 12,15$ \\
\hline CB-20G & $\pm 2,83$ & $37,65 \pm 8,63$ & $609,72 \pm 179,15$ \\
\hline CB-40G & $6,81 \pm 0,76^{*}$ & $53,20 \pm 3,51 *$ & $229,10 \pm 31,86$ \\
\hline CB-60G & $3,70 \pm 0,10^{*}$ & $70,36 \pm 4,03^{*}$ & $232,00 \pm 25,22$ \\
\hline CB-20T & $\pm 0,33 *$ & $\pm 1,19$ & $211,41 \pm 12,33$ \\
\hline $\mathrm{CB}-40 \mathrm{~T}$ & $\pm 0,36^{*}$ & $70,47 \pm 4,16^{*}$ & $423,12 \pm 9,07$ \\
\hline CB-60T & $4,85 \pm 0,64^{*}$ & $72,89 \pm 3,90^{*}$ & $238,38 \pm 18,59$ \\
\hline
\end{tabular}




\section{9 a 22 de outubro de 2014 \\ Florianópolis/SC}

\section{DISCUSSÃO}

A microestrutura apresentada pela CB (Figura 1) é muito similar a relatada na literatura. (BACKDAHL et al., 2006; BERTI, 2012; UL-ISLAM; KHAN PARK, 2012). A introdução de frações de Aloe vera no meio de cultura da bactéria $G$. hansenii produz alterações em toda a microestrutura dos hidrogéis variando a homogeneidade da superfície superior, como mostrado nos hidrogéis modificados com a fração $\mathrm{F}$, exibindo camadas lamelares que permeiam a estrutura interna, o recobrimento das fibras e o preenchimento dos poros dos hidrogéis, formulados com $\mathrm{G}$ e T, com uma camada microfibrilar que pode corresponder a presença dessas frações de Aloe vera. Outros materiais compósitos de CB-acemanana e CB-quitosana mostraram lamelas e regiões reticuladas similares às destacadas (KIM et al., 2011; RECOUVREUX, 2008). Saibuatong e Phisalaphong (2010) evidenciaram que em condições hidratadas o gel de Aloe vera permeia toda a superfície superior de membranas de CB (SAIBUATONG; PHISALAPHONG, 2010). Entretanto, nas condições analisadas essa permeação se observa na superfície inferior. Estudos destacam que a adição de polissacarídeos à base de glicomananas e/ou galatomananas no meio de cultura da $\mathrm{CB}$ afeta o processo deformação da fibra de celulose. Esses polissacarídeos aderem sobre a superfície das microfibrilas e se depositam sobre as fibras favorecendo a reticulação e o colapso das fibras de celulose (TOKOH et al., 1998; WHITNEY et al., 1998). Além disso, a microestrutura apresentada pela amostra CB-40T revelou um aspecto que remete a constituição física da pele. Nesta comparação, a primeira camada representaria a epiderme, a segunda camada a derme e a última camada a hipoderme (CLARK, 2014).

A adesão e a deposição de polissacarídeos sobre as fibras de celulose influenciam as propriedades mecânicas dos hidrogéis. As alterações observadas nas propriedades mecânicas dos hidrogéis formulados com as frações podem estar relacionadas ao aumento de fase amorfa $(A$. vera) na $\mathrm{CB}$, que ao se depositar sobre a superfície das microfibrilas, forma, em algumas regiões, pontos críticos suscetíveis à ruptura. Consequentemente, a quantidade de interações intermoleculares (ligações de hidrogênio), que conferem rigidez à estrutura, é reduzida. Além disso, a fase amorfa presente entre microfibrilas de CB pode permitir o movimento dessas fibras durante a aplicação de uma força de tração, aumentando assim a extensibilidade do material. A variação muito diferenciada, evidenciada pela $\mathrm{CB}-20 \mathrm{G}$, pode estar correlacionada com a heterogeneidade da distribuição da fração $\mathrm{G}$ no hidrogel. Ademais, a redução do módulo de elasticidade das amostras CB-20F, CB-60F, CB-40G, CB-20T e CB-40T se mostrou compatível com valores do módulo de elasticidade relatados para a pele $(5-12 \mathrm{kPa})$, como reportado na literatura (PAILLER-MATTEI; BEC ZAHOUANI, 2008).

\section{CONCLUSÃO}

A inserção de frações de Aloe vera in situ no meio de cultura da bactéria G. hansenii produziu hidrogéis cuja microestrutura foi notavelmente alterada, quando comparadas com a celulose controle, devido à incorporação dessas frações na celulose. Além disso, as propriedades mecânicas foram intimamente influenciadas por essa incorporação aumentando o alongamento de ruptura e reduzindo o módulo de elasticidade e a tensão de ruptura em comparação a celulose isenta de modificação. Essas alterações se mostraram interessantes por se assemelharem a pele, e 
dessa forma podem ser aplicadas em estudos de engenharia tecidual da pele.

\section{AGRADECIMENTOS}

Os autores agradecem a CAPES, CNPq e ao FINEP pelo apoio financeiro, ao LCME/UFSC pelas análises de MEV.

\section{REFERÊNCIAS}

BACKDAHL, H. et al. Mechanical properties of bacterial cellulose and interactions with smooth muscle cells. Biomaterials, v. 27, n. 9, p. 2141-2149, Mar 2006.

BERTI, F. V. Desenvolvimento de estruturas vasculares endotelizadas em Scaffolds de celulose bacteriana. 2012. 147 p Doutorado Programa de Pós-Graduação em Engenharia Química, Universidade Federal de Santa Catarina, Florianópolis, SC.

CLARK, R. A. F. Chapter 76 - Wound Repair: Basic Biology to Tissue Engineering. In: LANZA, R. et al. (Ed.). Principles of Tissue Engineering (Fourth Edition). Boston: Academic Press, 2014. p.1595-1617.

KIM, J. et al. Preparation and characterization of a Bacterial cellulose/Chitosan composite for potential biomedical application. Journal of Polymer Research, v. 18, n. 4, p. 739-744, 2011/07/012011.

PAILLER-MATTEI, C.; BEC, S.; ZAHOUANI, H. In vivo measurements of the elastic mechanical properties of human skin by indentation tests. Medical Engineering \& Physics, v. 30, n. 5, p. 599-606, Jun 2008.

RECOUVREUX, D. D. O. S. Desenvolvimento de novos biomateriais baseados em celulose bacteriana para aplicações biomédicas e de engenharia de tecidos. 2008. Tese (Doutorado). Programa de Pós-Graduação em Engenharia Química, Universidade Federal de Santa Catarina, Centro Tecnológico, Florianópolis, SC.

SAIBUATONG, O. A.; PHISALAPHONG, M. Novo aloe vera-bacterial cellulose composite film from biosynthesis. Carbohydrate Polymers, v. 79, n. 2, p. 455-460, Jan 202010.

TOKOH, C. et al. Cellulose synthesized by Acetobacter xylinum in the presence of acetyl glucomannan. Cellulose, v. 5, n. 4, p. 249-261, Dec 1998.

UL-ISLAM, M.; KHAN, T.; PARK, J. K. Nanoreinforced bacterial cellulose-montmorillonite composites for biomedical applications. Carbohydrate Polymers, v. 89, n. 4, p. 1189-1197, 2012.

WHITNEY, S. E. C. et al. Structural aspects of the interaction of mannan-based polysaccharides with bacterial cellulose. Carbohydrate Research, v. 307, n. 3-4, p. 299-309, Feb 1998. 
19 a 22 de outubro de 2014

Florianópolis/SC 